\title{
Do corpo produtivo ao corpo rascunho: aproximações conceituais a partir de relações entre corpo e tecnologia
}

\author{
Dulce Filgueira de Almeida, ${ }^{*}$ \\ Ingrid Dittrich Wiggers** \\ \& Carolina Nascimento Jubé***
}

Resumo: O presente artigo tem o propósito de examinar relações entre "corpo e tecnologia" no contexto do projeto social moderno, tomando como referência as noções de "corpo produtivo" e "corpo rascunho". A análise é desenvolvida por meio de fontes bibliográficas do campo da sociologia do corpo, permeando esse debate com autores da área de educação física. O conceito de corpo rascunho revelou-se heurístico para entendimento de relações do corpo com processos tecnológicos, em nossa época. Concluiu-se, preliminarmente, que a concepção de corpo sofreu mudanças e representações distintas ao longo da história, mas, atualmente, tais modificações acontecem de forma rotineira, produzindo uma noção fluida, segundo a qual poder-se-ia ser, a qualquer momento, o que se desejasse ser.

Palavras-chave: corpo; tecnologia; cultura; sociologia; educação física.

\section{A parábola de Frankenstein}

[...] as tecnologias da informação culminam finalmente na intervenção de uma humanidade modificada. A fronteira desaparece entre o sujeito e o objeto, o humano e a máquina, o vivente e o inerte, o natural e o artificial, o biológico e o protético.

Le Breton, 2012, p. 26.
Recebido: 03.07.13

Aprovado: 22.11 .13

\author{
* Professora \\ Associada II da \\ UnB. Credenciada \\ pelo Programa de \\ Pós-Graduação em \\ Educação Física da \\ UnB. \\ <dulce.filgueira@ \\ gmail.com>
** Professora
Associada II da UnB. Credenciada pelo Programa de Pós-Graduação em Educação Física da UnB.
<ingridwiggers@ gmail.com>

\begin{abstract}
A s políticas de corpo que experimentamos hoje se constituem, citando Lévy (1996: 27), "[...] uma aventura de autocriação que sustenta nossa espécie", o que nos sugere problematizações: de que corpos falamos? Que corpos experimentamos? Qual é o sentido dos processos de autocriação de corpos?
\end{abstract}

Esses questionamentos nos remetem à imagem da criação de Frankenstein, delineada por Mary Shelley, em 1818, no livro Frankenstein or the modern Prometheus. A obra foi estruturada em torno da descrição de um exótico experimento científico, que consistiu em articular fragmentos de corpos para formar uma nova unidade humana. 0 modelo baseou-se na proporção harmoniosa dos membros e na beleza dos traços su-
*** Pesquisadora do
Núcleo de Estudos
do Corpo e Natureza
(Necon) e do Grupo
de Pesquisa sobre
Corpo e Educação
(Imagem), da Uni-
versidade de Brasília
(UnB). Mestre em
Educação Física pela
UnB. <caroljube@
gmail.com> 
1. David Le Breton é doutor em antropologia e professor da Université Marc Bloch, em Estrasburgo (França). Possui vinte livros publicados, entre eles: Corps et sociétés: essai de sociologie et d'anthropologie du corps (Paris, Méridiens-Klincksieck, 1985); Anthropologie du corps et modernité (collection "Sociologie d'aujourd'hui", Paris, PUF, 1990); Passions du risque (collection "Traversées", Paris, Métailié, 1991); La sociologie du corps (collection "Quesais-Je?", Paris, PUF, 1992). L'adieu au corps, (collection "Traversées", Paris, Métailié, 1999). Assim como cerca de 70 artigos publicados, além de capítulos de livros, prefácios e outros trabalhos. geridos em tempos clássicos. Mas a experiência produziu, ao contrário, uma criatura monstruosa.

A peça literária, para além da crítica aos excessos científicos que se anunciavam no período, repousa sobre outra intuição mais oculta e difusa, na qual partes de cadáveres formam um corpo, isto é, fabricam uma vida superior, uma espécie de super-homem. A imagem desse herói mitológico produz ambiguidade em nossos sentimentos porque, por um lado, a morte da criatura a converte em vítima da trama, cujo roteiro expressa um espírito de época, mas, ao mesmo tempo, o monstro parece repercutir um significado suspeito para o sentido de humanidade. A popularidade da criação de Shelley foi percebida pelo cinema, que produziu, desde a primeira versão dirigida por James Whale, mais de meia centena de adaptações (Coli, 2003). Essa imagem permanece viva, na condição de objeto clássico, de atenção do campo sociofilosófico, conforme a capturou Le Breton ${ }^{1}$ (2003), para a elaboração de sua ideia de corpo como rascunho. $\mathrm{O}$ autor refere-se a um corpo que está constantemente sendo reconstruído, remodelado, sofrendo intervenções que são, na maioria das vezes, resultados de processos científicos e tecnológicos tais como a robótica, a engenharia genética, as cirurgias estéticas, os implantes e, notadamente, as ginásticas.

Assim, para dar sentido ao corpo na atualidade, sobretudo no projeto moderno de sociedade ocidental, que se constitui por meio do estabelecimento de redes e por uma contínua fluidez (Bauman, 2001), acreditamos ser profícuo estabelecer suas relações com a ciência e a tecnologia. Habermas (1973) considerou a ciência e a técnica como as forças produtivas mais relevantes nas sociedades contemporâneas desenvolvidas. Nessas, domina o que ele designou de "consciência tecnocrática", baseada na ciência e na técnica como ideologia que se articula oportunamente à produção industrial. 0 desenvolvimento tecnológico representa, sobretudo nos dias de hoje, um fenômeno de escala global, cujo impacto é percebido e esperado em todas as esferas da vida humana (Castells, 1990).

Diante desse cenário, o presente artigo tem o propósito de desenvolver uma discussão sobre as relações entre "corpo e tecnologia" no contexto do projeto social moderno, tomando por referência as noções de "corpo produtivo" e "corpo rascunho". Nosso pressuposto de discussão é que o encontro entre corpo e tecnologia, na atualidade, ou seja, na "modernidade líquida" (Bauman, 2001), ampliou as possibilidades de construções corporais, propiciando a passagem do paradigma do corpo produtivo para o paradigma do corpo rascunho, tornando o corpo passível de ser corrigido, reescrito, retocado e reinventado, de acordo com o desejo do sujeito. Para tanto, exploram-se contribuições teóricas de autores da sociologia do corpo, destacadamente Le Breton (2003; 2004; 2006; 2012), permeando esse debate com autores da área da educação física, como Soares (2006; 2011; 2012), Silva (1996; 2001) e Daólio (2011). 
Ao mesmo tempo em que não pretendemos esgotar o tema, esperamos articular uma análise do corpo feita no campo das ciências sociais e humanas com a da educação física, o que poderá indicar perspectivas para a compreensão do tema e possibilitar novas reflexões para ambos os campos.

\section{O corpo produtivo}

Na Modernidade, o corpo adquire notadamente um caráter instrumental, que é representado por uma visão de mundo que destaca a sua dimensão puramente física, em associação à negação de sua dimensão espiritual (Suassuna et alii, 2005). Essa perspectiva contrasta com a do período anterior, quando o corpo humano foi impregnado de pecado pelo domínio da religião católica em território europeu. O conceito moderno de corpo estruturou-se com fundamento na concepção cartesiana, constituído originalmente no campo das ciências naturais. $\mathrm{O}$ advento da ciência moderna reforçou uma concepção dualista de corpo, que obteve respaldo no modelo cartesiano de conhecimento. Fundamentado na matemática, Descartes questionou os sentidos como mediadores do conhecimento (Laso, 1986). Segundo o filósofo, o conhecimento seguro se apoia nos princípios da razão. O progresso científico validou o conhecimento no âmbito da razão e limitou-o ao mundo físico, observável e mensurável. O ser humano seria, por coerência, a soma de duas naturezas: o corpo físico e a alma - res extensa e res cogitans (Descartes, 1986).

Acontecimentos anteriores ao período moderno concorreram para a consolidação dessa política de corpo. As chamadas anatomias públicas do Renascimento europeu constituíram práticas de produção de conhecimento e visualização do corpo, que colaboraram significativamente para a definição de fundamentos da ciência empírica moderna. Antes disso, o corpo havia sido estudado apenas por meio de métodos escolásticos, que eram baseados na interpretação de textos clássicos. O teatro anatômico renascentista surgiu, assim, como prática de conhecimento sobre o corpo na passagem do período medieval para o moderno. Ainda que o nosso foco seja considerar o corpo no contexto da Modernidade, vale lembrar uma interessante passagem mencionada por Monteiro, quando registra que:

Bastante comum nos principais centros acadêmicos da Europa Ocidental, as anatomias eram rituais públicos peculiares e envolviam música e decoração luxuosa, além do espetáculo do corpo dissecado (Monteiro, 2011: 643).

Mais do que difusão do conhecimento entre os praticantes da Medicina, construída com base na observação direta do corpo, esses espetáculos eram carregados de dramaturgia, pois o corpo era encenado como centro de uma nova ordem simbólica do mundo. 
2. Os principais aspectos que caracterizam a Modernidade foram identificados por Touraine (1994), como sendo a "destruição das ordens antigas", o "triunfo da racionalidade subjetiva ou instrumental" e o "processo de subjetivação". Apesar da ressalva que consagrou Berman (1987), diante da busca de compreensão de um período que ainda se encontraria em curso, acrescenta-se a esses aspectos uma tendência inédita à universalização de valores, normas e práticas.
A prática da anatomia, sobretudo a noção de corpos dissecados, contribuíram para alimentar um novo projeto de construção corporal. Aqui podemos dizer que o corpo entra em cena, colaborando as considerações de Foucault (1992: 34) no sentido do entendimento de que, a existência do indivíduo na modernidade é perpassada pelo reconhecimento dele próprio no interior de seu organismo, forjando uma "armadura de seus membros em meio a toda nervura de sua fisiologia [...]". Isto quer dizer que, antes de tudo, o caráter orgânico do indivíduo é tomado como prevalecente. Agora temos corpos materialmente definidos, distintamente do que havia no passado.

Na mesma direção, Le Breton (2006), retomando algumas ideias presentes no pensamento foucaultiano, diz que a mediação do corpo pela ciência moderna estabelece, de maneira arbitrária, uma separação entre o indivíduo e seu corpo, pressupondo que este teria um fim em si mesmo. Tal ideia se fundamenta no conhecimento biomédico forjado no projeto moderno, que sustenta com primazia a visão do corpo nas sociedades ocidentais. O autor afirma ainda que, para a consolidação dessa concepção, foi necessário o abandono de valores tradicionais, isto é, a ruptura com o paradigma da sociedade medieval².

Em adição, entre os acontecimentos que se destacam no início do período moderno, encontramos as revoluções político-ideológica e econômico-tecnológica, pelas quais passaram a França e a Inglaterra, respectivamente. Tais acontecimentos culminaram com o processo de industrialização da sociedade, que também concorreu para a consolidação de uma concepção instrumental de corpo. A concretização dos novos objetivos políticos e econômicos transita entre o controle ideológico e o controle corporal, com ênfase no corpo dos indivíduos (Foucault, 2007). A experiência do corpo, por conseguinte, seria mediada por atividades que contribuíssem para um melhor funcionamento do organismo, visando ao adestramento corporal. A sensibilidade do ser humano deveria ser controlada para suportar a carga de trabalho que compete a cada um nas relações de produção do capitalismo, tornando o corpo dócil e útil. Essa experiência deveria, sobretudo, buscar assegurar o controle das populações, por meio da implementação de políticas de saúde. Nessas políticas ancoradas na concepção cartesiana, os corpos dos indivíduos foram abordados como objetos.

Em decorrência dessa trajetória histórica e política, o corpo passou a ser tratado não apenas como peça para dissecações e estudos médicos, mas também como um instrumento de produtividade, a fim de alimentar o processo de industrialização. À imagem criada por Mary Shelley pode-se acrescentar outra típica do cenário simbólico moderno: a da maquinização da vida, representada exemplarmente no filme Tempos modernos (1936). O filme, dirigido e protagonizado por Charles Chaplin, foi exibido pela primeira vez em 1936 e tece, de forma brilhante, uma crítica ao processo de 
industrialização. O ser humano confunde-se a tal ponto com o maquinário industrial que, na representação cinematográfica, o seu corpo ocupa o lugar de uma peça na engrenagem do sistema de produção. Com efeito, o corpo moderno tornara-se

[...] um fragmento, uma parte de um sistema de produção mais complexo, o que conduziu à sua descaracterização e perda de identidade (Rodrigues, 2008: 13).

Podemos inferir da passagem mencionada, que o corpo no projeto moderno assumiu outros contornos, constituindo outras identidades, diversas de suas formas de identificação ou das identidades do passado, em que não havia a clara separação entre corpo e alma ou corpo e espírito. Em face do acelerado processo de industrialização moderno, o corpo assume, com efeito, outros contornos. É material, concreto, produtivo. Instauram-se outras concepções de corpos, que submetidos ao processo de produção capitalista, tendem a se mercadorizarem e se alienarem. De acordo com Amaral (2011), a alienação do indivíduo pelo trabalho na sociedade capitalista também se produz na dimensão de sua corporeidade. Ou seja, essas outras concepções de corpo, submetidas à lógica e à divisão do trabalho capitalista, influenciam o desenvolvimento humano em todos os aspectos, notadamente em sua corporeidade.

É precisamente nesse contexto que vem à tona o conceito de corpo produtivo, segundo o qual

o corpo não é mais aquele que se esforça ou não para ser feliz e realizado, o que é nobre ou vassalo, que se pune ou que se salva. 0 corpo do indivíduo é a concretização da força de trabalho, mercadoria fundamental nesta nova ordem [...] (Silva, 1996: 246).

Com compreensão similar, Soares (2012) analisou as primeiras manifestações do corpo como instrumento de produtividade, com base no estudo sobre as interpretações e utilizações do corpo no início do período fabril. A autora evidenciou que as sociedades ocidentais do fim do século XVIII e início do século XIX adotavam simbolismos de destreza e habilidade, bem como se utilizavam da educação do corpo como instrumento para viabilizar o ideal de produtividade, próprio do capitalismo, assim como a defesa da pátria. Os corpos tornaram-se, assim, isentos de história, cultura e desejos, tendo somente um fim, ou seja, servir aos ideais de produtividade. Diz Soares:

O corpo individual enquanto unidade produtiva, máquina menor da engrenagem da indústria capitalista, passa a ser então uma mercadoria $^{3}[\ldots]$ (Soares, 2012: 27),

tornando-se um objeto determinado pelas novas relações de produção, ou seja, uma espécie de instrumento com um valor utilitário nas mãos do capital. Nesse cenário,

3. Conceito retirado pela autora da obra O capital, de Karl Marx (1867). Para Marx, "a mercadoria é, antes de mais nada, um objeto externo, uma coisa que, por suas prioridades, satisfaz necessidades humanas, seja qual for a natureza, a origem delas, provenham do estômago ou da fantasia. Não importa a maneira como meio de subsistência, o objeto de consumo, ou indiretamente como meio de produção".

"Neste caso do 'corpo', ele tomará a forma de mercadoria de modo indireto, ou seja, enquanto meio de produção" (Soares, 2012: 27). 
procuravam-se as respostas e as ações políticas para a melhor eficiência desses corpos-objetos dentro das fábricas.

Como vimos, o corpo tornara-se um instrumento de produção que garantiria a consolidação do modelo econômico emergente. A fim de que as elites dominantes se sustentassem no poder, era preciso promover discursos e políticas para uma educação dos corpos, coincidindo com políticas sanitárias e discursos militares eficazes. Esses discursos dariam às demais parcelas da sociedade uma vida moral sem vícios, organizada por regras e garantiriam um corpo higiênico e eugênico, visando à manutenção da ordem e a defesa da pátria. Era imperativo, portanto, despender investimentos para que o corpo fosse adestrado, disciplinado, higienizado, moralmente aceito, com o intuito de que exercesse sua função de produção. Estes investimentos vieram na forma da medicalização da sociedade, da consolidação e do controle das instituições escolar e familiar e da necessidade da educação do físico para a manutenção de bons instrumentos de produção para as indústrias (Soares, 2012).

Sob os auspícios dessas políticas, o movimento ginástico europeu se firmou como parte integrante dos novos códigos de civilidade, viabilizando a correta educação do corpo. O corpo do fim do século XVIII e início do século XIX era treinado para adquirir força, armazenar e poupar energia, tornando-se biológico, higiênico e controlável, assumindo, assim, os valores preconizados pela classe dominante. O corpo passa a ser adestrado e conformado como objeto de estudo da ginástica, posteriormente designada de educação física. A ginástica científica, por seu turno, transforma-se na promotora dos princípios de higienização e eugenização dos corpos, modelando-os e adestrando-os. Instaura-se uma nova ordem coletiva, que deve ser respeitada desde a infância (Soares, 2012). O corpo passa a ser

[...] o primeiro lugar onde a mão do adulto marca a criança, ele é o primeiro espaço onde se impõem os limites sociais e psicológicos que foram dados a sua conduta, ele é o emblema onde a cultura vem inscrever seus signos como também seus brasões (Vigarello, 1978: 399).

Em simetria com os referenciais da classe dominante, a ginástica científica destacou-se por seus princípios de ordenamento, disciplinadores e metódicos. Essa ginástica tem como um de seus principais objetivos o controle dos corpos e a atenção à saúde do indivíduo e da sociedade como um todo. A boa condição de saúde do corpo passou a ser responsabilidade do próprio sujeito e essa deveria ser alcançada por meio da prática de exercícios, do treinamento, da correção e modelagens dos corpos de acordo com o modelo ginástico da época. Essas práticas desenvolveram-se sob os moldes da instituição militar e sob a inspeção da classe médica, na tentativa de transformar o corpo artístico, funambulesco em um corpo disciplinado 
e útil. Com efeito, esse movimento deslocou a compreensão de corpo relacionado à cultura popular e circense, presente no período medieval e moderno, e impôs a noção de corpo associada à visão utilitarista que predominou no período posterior. Ou seja, o corpo passou a ser tratado de forma racional, visando à sua utilização produtiva. Isso propiciou um grau de importância considerável à educação física como disciplina científica, que buscou, a partir de então, se assemelhar à medicina e, mais particularmente, à fisiologia.

Consoante uma literatura de cunho mais crítico, pode-se conjecturar que a concepção de corpo matizada ao longo da história ocidental moderna pode ser evidenciada no Brasil por meio da noção de esporte espetáculo, salientando o boom esportivo que marcou o país desde o início do século XX. Naquele tempo, relacionavam-se as práticas esportivas, não apenas ao divertimento e entretenimento, mas também às temáticas da eugenia, da higiene e da educação, presentes na Europa desde o fim do século XVIII e início do século XIX, compondo um projeto de modernidade para o Brasil.

Essa febre ou civilização esportiva expressou-se com mais vigor após a Primeira Grande Guerra, trazendo com ela uma euforia pelo moderno, pelos novos modos de ver e de ser visto, de agir e de se vestir, de lidar com as temporalidades. Maneiras de estar e de participar em uma sociedade urbana e de massas [...] (Linhales, 2009: 28-29).

A visão de corpo associada ao esporte correspondia a um ideal civilizatório próprio do projeto moderno. À educação física caberia o papel de educar, otimizar e operacionalizar o funcionamento do corpo, sendo necessária a sua submissão ao controle médico da época, que coincide com a consolidação do modelo urbano-industrial no Brasil. Portanto, vale registrar que, além de se revestir de uma face instrumental, o corpo produtivo integrou-se a uma política e a uma economia de perspectivas abrangentes, aliada ao projeto moderno e em cuja base se assentava a visão ocidental e capitalista. Tratou-se de um processo que visava à fabricação do "Homem Novo", preparado para atender às contingências das transformações em curso (Schneider, Ferreira Neto, 2008).

O "Homem Novo", submetido ao rígido controle corporal, por seu turno, demanda, paradoxalmente, a necessidade de libertação, o que faz com que as práticas corporais figurem também como espaços de compensação, que podem ser ilustrados, por exemplo, pela disseminação de terapias corporais alternativas. Entretanto, ainda que as práticas corporais gradativamente se emancipem do campo da medicina, visando à promoção do prazer, da liberação do corpo e do bem-estar, a concepção de corpo hegemônica é a de ser elegante, magro e dinâmico, compatível com os ideais de rendimento e controle inerentes ao modo de produção capitalista. O ideal de corpo 
burguês vem se constituindo como mais um produto de consumo veiculado nas campanhas publicitárias. O corpo é revalorizado no plano das aparências e invade o domínio público. Com efeito, o que se observa nos dias de hoje é um aumento da procura e da oferta de práticas corporais tratadas como mercadoria. Essas práticas corporais, ao contrário de um projeto de humanização, voltam-se para a desintegração, fazendo do corpo um objeto estratégico de expansão do capital, ao tempo em que forjam outras identidades.

\section{O corpo rascunho}

Com o avanço da produção do conhecimento científico, pesquisas sobre as relações entre "corpo e sociedade" passam a atender à outra racionalidade. Neste âmbito, Mauss (2005) ocupa um lugar original no debate, particularmente ao propiciar a interlocução entre distintas áreas de conhecimento nos estudos voltados para o corpo. O autor reitera a interpretação de que

o corpo é o primeiro e o mais natural instrumento do homem [...], o primeiro e mais natural objeto técnico, e ao mesmo tempo o meio técnico do homem é seu corpo (Mauss, 2005: 211).

Em seu estudo acerca das técnicas corporais, ele afirma que as técnicas do corpo são

[...] as maneiras como os homens, sociedade por sociedade e de maneira tradicional, sabem servir-se de seus corpos (Mauss, 2005: 211).

Sob essa visão, o corpo é analisado como um objeto técnico, como instrumento que pode ser, ao mesmo tempo, tradicional e eficaz em sua realização. Não obstante a ênfase na técnica, o autor identifica o corpo como "fato social total", o que implica em dizer que a compreensão de quaisquer das técnicas corporais realizadas pelo ser humano pode ser encontrada nas dimensões fisiológica, psicológica e social. O corpo pode ser interpretado como fato social total, por ele ser constituído cultural e socialmente, para além de suas características genotípicas.

O corpo, portanto, apresenta elementos individuais (fisiológicos e psicológicos) e sociais (históricos e culturais) em sua constituição, devendo ser interpretado como totalidade. Nesta direção, parece pertinente adotar a compreensão de fato social total, de Mauss (2005), segundo a qual um estudo que envolva o corpo humano pressupõe o estabelecimento dialógico entre distintos campos disciplinares. Deve-se ter atenção não somente às visões que preponderaram até então, quais sejam as de que os estudos sobre o corpo deveriam ocorrer sob a égide de disciplinas como a biologia e a psicologia, mas perceber que no corpo também estão inscritas todas as regras, todas 
as normas e todos os valores de uma sociedade, pois ele é o meio de contato primário do indivíduo com o ambiente (Daólio, 2011).

A perspectiva maussiana serve como base para a construção de um conjunto de compreensões que mais tarde desembocam na sociologia do corpo (Le Breton, 2006). A essa perspectiva foram somados esforços para entender o corpo como objeto de estudo sociológico e, neste particular, em que medida os elementos sociais e individuais servem para caracterizar o significado de corpo que cada um de nós constrói. Ao considerar o pressuposto de que o corpo é simultaneamente uma representação individual do ser humano e um resultado da expressão coletiva (Le Breton, 2006), admite-se que os aspectos individualizantes que constituem as técnicas corporais dos sujeitos estão relacionados às formas de representações coletivas, entendidas como as maneiras comuns presentes em cada sociedade.

Por pensarmos o corpo de forma ampliada e contextualizada no meio em que vive o sujeito, consideramos que dificilmente se conseguiria tomar o corpo como objeto de estudo sem abordar os processos socioculturais que definem os padrões ou modelos de corporeidade. No Renascimento, por exemplo, as pessoas demonstravam uma preocupação com a presença de seus corpos em público, utilizando roupas e adereços como instrumentos de representação do status e prestígio social. Conforme Silva,

[...] o trato com o corpo passa a adquirir importância para as relações que se travam com os outros, destoando dos períodos anteriores em que o fundamento era a relação consigo próprio, ainda que fosse para evitá-lo, como no caso da Idade Média, para não incorrer em pecado perante as leis divinas (Silva, 1996: 246).

Na esteira das lógicas sociais, por conseguinte, o corpo se modifica de acordo com a posição ocupada por cada sujeito em sua classe ou grupo social. Nas classes menos favorecidas, o corpo é tratado como instrumento de trabalho e a força física garante o seu bom funcionamento. Em contraste, nas classes sociais em que o trabalho é prioritariamente intelectual, o corpo apresenta outra conotação e requer outros tipos de cuidados. Essas observações convergem com as análises apresentadas por Bourdieu (2006) e Boltanski (1974), que associam os gostos de classe e os estilos de vida aos usos sociais dos corpos.

Na medida em que subimos na hierarquia social, que o nível de instrução cresce e que diminui correlativa e progressivamente a importância do trabalho manual em relação ao trabalho intelectual, o sistema de regras que rege a relação do indivíduo com o corpo é igualmente modificado. Quando a atividade profissional é essencialmente uma atividade intelectual que não exige nem força nem competência física particular, os sujeitos sociais tendem a estabelecer 
uma relação consciente com o corpo e a tomar mais cuidado com as sensações orgânicas e as expressões dessas sensações, e, segundo lugar, a valorizar a "graça", a "beleza", a "forma física", em detrimento da força física (Boltanski, 1974: 22).

Assim, as marcas e expressões corpóreas manifestam por si os lugares sociais ocupados pelos corpos. Retratam, portanto, o corpo experimentado, vivido, do trabalho ou do não trabalho. Enfim, o complexo emaranhado dos estilos de vida inclui uma corporeidade e expressa um habitus, conforme o conceito de Bourdieu (1983). Nestes termos, o corpo é um fenômeno social que se relaciona com a experiência vivida por cada sujeito, não sendo meramente representado, mas sim experimentado. Esse é também um corpo transformado e está suscetível a mudanças com a finalidade de satisfação de necessidades básicas. Pode ser mais inclinado a produzir a própria subsistência, ou com tendência a se modificar para que possa ser inserido em um determinado grupo social.

Ao considerar esse processo de constituição do corpo simbólico, destacamos a corporeidade como perspectiva que contempla todas as dimensões do corpo:

[...] física (estrutura orgânica-biofísica-motora organizadora de todas as dimensões humanas), emocional-afetiva (instinto-pulsão-afeto), mental-espiritual (cognição, razão, pensamento, ideia, consciência) e a sócio-histórico cultural (valores, hábitos, costumes, sentidos, significados, simbolismos) (João \& Brito, 2004: 266).

De acordo com os autores, tais dimensões encontram-se indissociáveis e constituem a corporeidade do ser humano. A corporeidade é tida como a forma do humano ser-no-mundo, observando a subjetividade, o mundo vivido, os valores existenciais, carregados de história e símbolos em busca da satisfação dos desejos.

O corpo é plural uma vez que a vontade do indivíduo assim deseja e porque ele o concebe como material de uma produção deliberada de si. Torna-se artífice de si, construtor da sua própria aparência física, inventor das formas que o revelam ao mundo (Le Breton, 2004: 252)

O corpo ancora-se, portanto, a uma estrutura antropológica que materializa o ser humano.

Ao seguir essa linha de argumentação, cabe ressaltar que, por estar na intersecção de todos os aspectos que formam a cultura, o corpo situa-se em um ponto de encontro com os processos tecnológicos. As transformações na realidade social, por meio da sociedade em redes, cujas características, como globalização das atividades econômi- 
cas, flexibilidade dos empregos, organização em rede, transformação das percepções de tempo e espaço, cultura da virtualidade e presença significativa da mídia, conferem uma singularidade à nossa conjuntura e constituem uma modernidade fluida em que os processos de construção da identidade se fundamentam na disjunção sistêmica entre o local e o global (Castells, 2002). Tais processos caracterizam-se, atualmente, por um intenso desenvolvimento, cuja trajetória não encontrou limites desde o Século das Luzes (Castells, 1990).

Embora a utilização das máquinas para a produção não represente mais novidade entre nós, vivemos hoje sob um ambiente de significativa tecnicalidade em diversas esferas do cotidiano, envoltos em um cenário de mecanização da vida em geral. 0 ambiente técnico parece tomar gradativamente o lugar do ambiente natural, o que implica em novos códigos, habilidades e aptidões, enfim, outras culturas.

Nesta sociedade povoada de homens e de máquinas, a técnica mediatiza (e, por consequência, modela, "dá forma") às relações humanas. Não só no mundo do trabalho o homem produz através da máquina, mas também no campo das interações pessoais ou da transmissão cultural, os objetos técnicos são os intermediários entre os homens. O homem está menos presente em suas ações. Definitivamente separado do processo de seu trabalho pela produção industrial, o homem comunica-se a distância através do telefone e cristaliza sua fala e sua imagem em fitas magnéticas, que se transformam em mercadoria consumida por outros homens (Belloni, 2005: 53).

Esse quadro tem efeitos sobre a corporeidade. Diante da sofisticação e aceleração dos processos tecnológicos, destacamos a passagem do "corpo produtivo" ao "corpo rascunho". Esse percurso de análise se deve à capacidade que a tecnologia, atualmente, tem de fornecer uma transformação e até mesmo uma reinvenção do "eu", ou melhor, da imagem do "eu", volatilizando as imagens corporais, tal qual a metáfora da "vida líquida" (Bauman, 2001). Essa metáfora ilustra uma mudança nas sociedades ocidentais, a da passagem do paradigma da produção e do trabalho para o do consumo.

Os "consumidores" e os "objetos de consumo" são os polos conceituais de um continuum no qual estão colocados todos os membros da sociedade de consumo e sobre o qual eles vão e vêm todos os dias" (Bauman, 2001: 18).

A sociedade que se constitui por "produtores" e "consumidores", produz desejos, seduções, prazeres e vontades fugazes, que estando ausente de qualquer tipo de normalização desses anseios voláteis, torna as sensações em necessidades a serem "subjetivamente experimentadas". Portanto, integram esse cenário as falsas necessidades. 
A ideia de "luxo" não faz muito sentido, pois a ideia é fazer dos luxos de hoje as necessidades de amanhã, e reduzir a distância entre o "hoje" e o "amanhã" ao mínimo - tirar a espera da vontade (Bauman, 2001: 90).

Caberia aos indivíduos ainda, sob essa perspectiva, a prerrogativa de gerir seus próprios corpos. O corpo que deve se adequar a essa nova situação é um

[...] corpo flexível, absorvente e ajustável, pronto para viver sensações ainda não testadas e impossíveis de descrever de antemão (Bauman, 2001: 91),

mas que apenas encontrará uma satisfação momentânea para esses desejos. O corpo como objeto de desejo é considerado também um acessório, um artefato da presença, que implica na encarnação de si e que alimenta o desejo, em cada um, de se reapropriar de sua existência e, eventualmente, de criar outra identidade - provisória ou não -, mas que aparece como mais favorável ao sujeito, em determinado contexto ou perante o seu grupo social. Pode ser considerado, até mesmo, como um corpo que, por possuir uma parte "ruim" e "ultrapassada", precisa ser corrigido ou superado (Jubé, 2010).

A superação do corpo humano, com efeito, permitiu a sobrevivência, a evolução e o progresso. Ao longo da trajetória humana, foi preciso sobrepujar as fragilidades corporais para dar continuidade ao sentido de desenvolvimento nos moldes da sociedade ocidental moderna.

Essa superação do corpo vital, uma vez que reconhecidamente os antepassados filogenéticos Homo sapiens não eram seres dominantes em seu ambiente. Pelo contrário, sua fragilidade obrigou-os a procurar soluções inteligentes, ágeis e diversificadas para fazer face às frequentes e reais ameaças a que estavam sujeitos (Rodrigues, 2008: 13).

Já em tempos de modernidade líquida, não é mais o caso de contentar-se com o corpo que se tem, mas de realizar modificações em suas bases para que ele se equipare à ideia que fazemos dele (Le Breton, 2003).

Os cuidados com o corpo contemporâneo, desde a cosmética às cirurgias plásticas, body buildings e transformismos de diversas ordens mostram que a experiência do corpo e seus investimentos afetivos e estéticos se voltam menos para o que ele é e para o que seriam os seus estados naturais, do que para o que ele pode vir a ser, o que nele pode ser transformado, esculpido, modelado. E tal experiência do corpo não pode ser facilmente definida como me- 
nos autêntica ou verdadeira, pois na ordem na aparência e da imagem, um corpo pode muito bem valer pelo que ele não é. Ou ainda, o que ele é reside cada vez mais naquilo que ele se torna e naquilo que dele se mostra e se dá a ver.[...] Somos tão mais autênticos quanto mais próximos estivermos daquilo que desejamos ser. $\mathrm{E}$ neste mundo em que nossos corpos e almas ganham a plasticidade das imagens, a autenticidade também reside naquilo que se parece "ser" (Bruno, 2004: 25).

Os corpos desejados seriam aqueles que se apresentam de forma imperativa nas imagens construídas socialmente, ou seja, corpos atléticos e perfeitos. São corpos submetidos às ginásticas ${ }^{4}$, regimes e design - body art, body building (Le Breton, 2004). 0 bug muscular ilustra esse movimento, pois

[...] entre heróis e mastodontes, os praticantes de musculação procuram materializar em seus próprios corpos as representações com as quais se identificam. A musculatura hipertrofiada vai ser o ponto de convergência de um processo de afirmação e diferenciação de identidades [...] (Fraga, 2011: 72).

O bug muscular propicia a definição de padrões corporais que conformam modelos de corpos masculinos e femininos, que passam a ser difundidos como ideais de aceitação e de êxito social. Consolidaram-se a partir da década de 1980, por meio da generalização das práticas de body building nos Estados Unidos, uma das manifestações contemporâneas mais relevantes da cultura do corpo (Courtine, 1995).

Acrescente-se ainda que, na conjuntura da sociedade em rede, a troca de informações se dá em velocidade estarrecedora, o que contribui para a produção de imagens corporais que se volatilizam. A imagem do corpo ideal é protagonizada por celebridades e divulgada pela publicidade, por espetáculos esportivos na mídia, brinquedos, revistas, programas de televisão, obras literárias, entre outros, alcançando mesmo as crianças, como é o caso das "bonecas-manequim" estilo Barbie (Brougère, 2000). O que se percebe, portanto, é uma hipervalorização da aparência física do corpo, que é corroborada pela excessiva exposição no espaço público, cujo molde é apresentado pela mídia e acaba por funcionar como miragens de um ideal corporal a ser atingido (Santaella, 2004).

Em pesquisa sobre representações e expressões corporais de crianças, entre sete e nove anos de idade, Wiggers (2012) observou que entre os autorretratos dos meninos se destacaram imagens corporais amplamente valorizadas pelas mídias, como, por exemplo, a do "fortão", "bad boy" e "herói da TV". A imagem do "fortão", nome usado pelas próprias crianças, foi caracterizada pela elevada estatura e musculatura avantajada, o que representa em nossa cultura corporal contemporânea, invoca-

\author{
4. Entendemos \\ "ginástica" como: \\ tipos de exercícios \\ físicos utilizados \\ para a melhora do \\ condicionamento \\ físico, para o \\ enrijecimento e \\ fortalecimento \\ muscular. Essa \\ prática pode ser \\ utilizada para moldar \\ o corpo dentro de \\ padrões estéticos \\ preestabelecidos \\ socialmente.
}


5. Expressão retirada de Silva (2001). ções e atributos masculinos do novo homem. Trata-se de provável espelho do body-builder, aquilo que Courtine (1995: 83) chamou de forma extrema "[...] de uma cultura visual do músculo". Em correspondência, entre os tipos exclusivamente femininos foram salientados a "loira-imaginária", a "magrela" e "a engraçadinha". O top destacou-se como traje preferido das meninas. A miniblusa colada ao corpo, que deixa a barriga à mostra, é geralmente acompanhada de short, minissaia ou calça comprida bem justa. Adereços, tamanquinhos de salto e batom acompanham o figurino. Observou-se, portanto, que as crianças de nossos dias estariam sendo submetidas a uma antecipação da "expectativa de corpo ideal" 5 , mediadas pelas interações sociais mais marcantes que as afetam, como, por exemplo, as mídias, que forjam a cultura corporal infantil. Se hoje, ponderou a pesquisadora, o objeto de desejo em alta no mercado é o corpo da jovem, não nos surpreenderemos se a necessidade desenfreada de novos produtos de consumo logo transformar a menina engraçadinha, "infantilmente" vestida de top e minissaia, no protótipo da menina-objeto, que poderíamos identificar como o próximo ícone da cultura de corpo burguesa.

Em consonância, outra pesquisa (Amaral, 2012) sobre manifestações sociais do corpo feminino concluiu que o discurso midiático, ao lado do discurso médico, foi indicado pelas participantes do trabalho de campo, como sendo a principal fonte

[...] de "saberes" sobre o corpo e divulgador de "certezas" sobre como gerir as corporeidades com vistas à saúde, à beleza, ao bem-estar e à felicidade, preservando, como ponto comum, a magreza (Amaral, 2012: 209).

Assim, por intermédio de imagens e discursos verbais e não verbais é exaltada a preocupação com o corpo, que além de uma obrigação para as mulheres, tornou-se sobretudo um estilo de vida da atualidade. A pesquisadora estabeleceu três dimensões para a análise do culto ao corpo e à magreza: práticas alimentares, por ela caracterizadas como a submissão a dietas alimentares; práticas interventivas, em que as muIheres se submetem a cirurgias médicas; e ainda práticas estéticas, definidas como a frequência a academias de ginástica.

Por conseguinte, para a definição e construção de um padrão corporal socialmente aceito, a educação física tem grande importância. Por meio de suas técnicas corporais, contribui para tonificação muscular, modelando corpos, tornando-os hipertrofiados ou mais fortes e, portanto, é capaz de contribuir para forjar o corpo desejado. As técnicas corporais combinam-se a outras, que vão desde a dieta, passando pelo body building até as cirurgias plásticas (Lévy, 1996; Fraga, 2011), e seu principal sentido diz respeito a um projeto de construção de corporal. 
O corpo afirma-se agora não por sua destreza produtiva (muito afetada pela disseminação das próteses), mas sim pela manifestação de uma identidade própria (Rodrigues, 2008: 20).

Ao mesmo tempo em que se deposita na educação física a expectativa de oferecer instrumentos para que cada um desenvolva um projeto de corpo, em consonância ou não com a cultura dominante, pergunta-se sobre a preparação e formação do professor de educação física. Uma pesquisa (Machado, Zanetti \& Moioli, 2011) realizada por meio de entrevistas, cujo objetivo foi identificar a percepção de professores de educação física acerca dos corpos transformados de seus alunos e ainda indagar possibilidades de trabalho e de atividades voltadas a estes corpos, obteve conclusões interessantes. Por um lado, os participantes demonstraram aceitação e consenso diante de atletas musculosos ou vigoréxicos. De outro evidenciaram resistência ao trato com outros tipos de corpos transformados, como os implantados, transplantados ou marcados de maneira voluntária, por meio de tatuagem, escarificação, cortes ou queimaduras. A reação dos entrevistados acerca do trabalho com deficientes mentais e físicos foi igualmente resistente, sendo que destacaram ainda o fato de se sentirem despreparados profissionalmente para o trato de um corpo diferente a esse nível (Machado, Zanetti \& Moioli, 2011).

Em adição, a referida pesquisa identificou que a metade dos entrevistados exibia um corpo correspondente aos padrões de força amplamente divulgados em tempos de hoje. Segundo os participantes, seus corpos eram mediados por exercitações diárias e prolongadas, considerando a importância do corpo como um "cartão de visita" do professor de educação física. O acesso às cirurgias plásticas também se evidenciou como um recurso ao qual recorreram os entrevistados para atingir um corpo belo e padronizado. Por fim, as mídias foram representadas como incontestavelmente certas, no âmbito dos discursos dos professores de educação física sobre o corpo. Os pesquisadores apontam a necessidade dos cursos de formação enfocarem criticamente o entendimento das características da relação homem-máquina, buscando-se uma contextualização das culturas vigentes e construção de práticas profissionais alternativas (Machado, Zanetti \& Moioli, 2011).

Para além de um objeto da educação física, o corpo rascunho ocupa um lugar de incorporação de tecnologias, onde as mesmas são capazes de quebrar barreiras da ciência, extrapolar obstáculos físicos da presença e até superar o modelo de vida que conhecemos hoje. As próteses corporais ${ }^{6}$, os enxertos, os silicones, entre outras novidades, são mais do que exemplos da fluidez entre o tecnológico e o corpóreo, pois tornaram-se os mais recentes objetos de consumo. Esses atravessam a pele, se instalam e se misturam ao organismo original com o intuito de repará-lo ou de melhorá-lo, de acordo com um padrão corporal socialmente aceito (Jubé, 2010). Sob esse paradigma,

6. Próteses
corporais "são
todos os recursos
tecnológicos que
permitem ao
corpo responder
às crescentes
solicitações do
entorno (automóvel,
celular, computador,
fax, escâner etc.)"
(Rodrigues, 2008:
17).


[...] o corpo é uma espécie de veículo da pessoa, o recinto material de sua interioridade, a relíquia indigna de uma velha humanidade ultrapassada (Le Breton, 2012: 24).

O corpo rascunho é, no âmbito dessa interpretação, maleável e suscetível a modificações, pode ser entendido como lugar de possibilidades, de reinvenções e da correção dos excessos (Le Breton, 2006).

Por conseguinte, a ideia de um corpo modificado por influências da infobiologia, tecnologia da comunicação, cultura cibernética e neurochipes, que dariam origem aos ciborgues, tem se vulgarizado cada vez mais. O ciborgue representa

[...] um passo decisivo em relação aos modelos tradicionais que arrastavam o artificial nos porões do submundo, incluindo pactos diabólicos, a juventude eterna, riquezas além da medida. Com uma tecnologia de biologia entalhada, pode-se ser jovem e tornar-se mutante (Canevacci, 2012: 55).

O amplo processo tecnológico sugere que a sua aceleração será capaz de engendrar processos de hibridação, nos quais nos tornaremos em híbridos de humano e inumano. A robótica, a biotecnologia e a nanotecnologia, que representam os três grandes investimentos de pesquisa atuais, pretendem, em comum, tanto manipular objetos infinitesimais como deslocar suas descobertas para o corpo humano como seu principal campo de aplicação.

De animais técnicos que usam ferramentas, passamos para o operário mecanizado de Chaplin, para trabalhador automatizado de Metrópolis, mas agora o que temos é um homem fundido às máquinas, um homem-máquina no sentido literal (Oliveira, 2003: 170).

Assim, no bojo dessas técnicas de remodelamento e de interferências, que já são muito populares no Brasil, a definição de um padrão corporal aparece como a possibilidade de singularização do corpo pelo sujeito, como parte de sua experiência no mundo social. Trata-se, portanto, de um corpo modificado e ressignificado por cada um de nós, um corpo que é rascunho. Como diz, em outras palavras, Le Breton (2006), a fim de definir seu projeto moderno de construção corporal, o ser humano pode submeter o seu corpo a qualquer tipo de intervenção ou técnica, afinal o corpo a ele pertence. Nesse projeto, os seres humanos definem suas escolhas individuais que estão, todavia, vinculadas a escolhas sociais. Sendo assim, é possível retomar a perspectiva sociológica a fim de entendermos a que são submetidas essas escolhas.

Se antes o corpo era explorado e alienado somente com a força de trabalho, a exploração que se coloca atualmente seria tão opressora 
quanto a anterior na medida em que aprisiona o corpo sob os consagrados padrões de beleza e do erotismo, que juntos estabelecem uma nova ética da relação com o corpo (Amaral, 2011: 47).

Volta-se, aqui, uma vez mais à consideração da clássica relação entre "indivíduo e sociedade", como abordagem heurística para a análise do corpo (Durkheim, 2010).

\section{Seria o corpo}

mais um traço de nossa liquidez?

Ao utilizarmos a metáfora da liquidez para entender a inserção do corpo no contexto social moderno, temos a intenção muito mais de suscitar debates do que apresentar certezas. Interposto como objeto de estudo de campos disciplinares distintos como sociologia e educação física, o corpo atende a dimensões biológicas, psicológicas e sociais, e transita entre concepções distintas, como a de um corpo produtivo e corpo rascunho que seguem, ao longo do processo social, expressando outras experiências, ainda que em grande medida podemos inferir que sejam perpassadas por processos tecnológicos. Isto porque, tanto no "corpo produtivo" quanto no "corpo rascunho" pode-se reconhecer fortes traços da presença da tecnologia, que representa um elemento relevante para o entendimento do corpo na sociedade em rede.

Os corpos situados no contexto de fluidez tornam-se projetos de construções socioindividuais à medida que buscam seguir padrões sociais ou mesmo se ancoram no modelo de perfeição ou de performance, calcado no rendimento. Ora, infere-se que aqui o corpo pode ser considerado um rascunho e está suscetível a contínuas modificações, sendo capaz de se reinventar e se ressignificar em razão das suas experiências e mesmo definir outras identidades aos sujeitos.

Trata-se do corpo rascunho de si, que sofreu mudanças e representações distintas ao longo da história social, mas que, agora, vê essas variações acontecerem a todo instante. É nesse ambiente de possibilidades de experiências infinitas que vemos nosso objeto de estudo como elemento para pensar a realidade social e para propor novos modos de compreendê-la e analisá-la.

Por fim, entendendo o ser humano como produtor de cultura, como sujeito que possui desejos e anseios, é possível perceber que seu corpo, para além de uma estrutura orgânica, sugerimos que novos estudos possam ser realizados sobre a temática. Estudos que se debrucem sobre o corpo, entendido de maneira mediatizada entre no âmbito de debate sociológico referenciado pela dicotomia indivíduo-sociedade, mas sobretudo àqueles que possam se orientar sobre a relação natureza-cultura, também tão cara à compreensão sociológica. 
Abstract: This article is intended to assess the relationships between "body and technology" in the context of the modern social project, taking the notions of "productive body" and "draft body" as reference. The analysis is developed through bibliographic sources of the field of sociology and the body, articulating this debate with authors of the physical education field. The concept of draft body proved to be heuristic for understanding the relationships of the body with technological processes in our time. It was preliminarily concluded that the conception of body underwent changes and distinct representations throughout history; however, currently, such modifications happen routinely producing a fluid notion, according to which one could be, at any time, what one wished to be.

Keywords: body; technology; culture; sociology; physical education.

\section{Referências}

AMARAL, Marcela Carvalho Martins. Culto ao corpo e estilo de vida entre as mulheres. 2011. Tese (Doutorado) - Programa de Pós-graduação em Sociologia. Departamento de Sociologia, Instituto de Ciências Sociais, Universidade de Brasília, Brasília.

- Culto ao corpo e estilo de vida entre as mulheres. Sociedade e Estado, v. 27, n. 1, Brasília, Jan./Abr. 2012, p. 209-209.

BAUMAN, Zygmunt. Modernidade líquida. Rio de Janeiro: Jorge Zahar, 2001.

BELLONI, Maria Luiza. O que é mídia-educação. 2. ed. Campinas: Autores Associados, 2005.

BERMAN, Marshall. Tudo que é sólido se desmancha no ar. São Paulo: Cia das Letras, 1987.

BOLTANSKI, Luc. Les usages sociaux du corps. Annales, v. 26, n. 1, 1974, p. 205-233.

BOURDIEU, Pierre. Sociologia. São Paulo: Ática, 1983.

_. La distinción: critério y bases sociales del gusto. Madrid: Taurus, 2006.

BROUGÈRE, Gilles. Brinquedo e cultura. 3. ed. São Paulo: Cortez, 2000.

BRUNO, Fernanda. A obscenidade do cotidiano e a cena comunicacional contemporânea. Famecos, n. 25, Porto Alegre, Dez. 2004, p. 22-28.

CANEVACCI, Massimo. Corpos polifônicos e tecnologias digitais. In: COUTO, Edvaldo Souza; GOELLNER, Silvana Vilodre (Orgs.). O triunfo do corpo: polêmicas contemporâneas. Petrópolis: Vozes, 2012, p. 33-64.

CASTELLS, Manuel. A sociedade em rede. 3. ed. São Paulo: Paz e Terra, 1990.

—. O poder da identidade. São Paulo: Paz e Terra, 2002. 
COLI, Jorge. O sonho de Frankenstein. In: NOVAES, Adauto (Org.). O homem-máquina: a ciência manipula o corpo. São Paulo: Cia das Letras, 2003. p. 299-315.

COURTINE, Jean-Jacques. Os stakhanovistas do narcisismo: body-building e puritanismo ostentatório na cultura americana do corpo. In: SANT'ANNA, Denise Bernuzzi de (Org.). Políticas do corpo. São Paulo: Estação Liberdade, 1995, p. 81-114.

DAÓLIO, Jocimar. Da cultura do corpo. 17. ed. Campinas: Papirus, 2011.

DESCARTES, René. O discurso do método. Lisboa: Edições 70, 1986.

DURKHEIM, Émile. Da divisão do trabalho social. 4. ed. São Paulo: Martins Fontes, 2010.

FRAGA, Alex Branco. Anatomias emergentes e o bug muscular. In. SOARES, Carmen Lúcia (Org.). Corpo e história. 4. ed. Campinas: Autores Associados, 2011, p. 61-77.

FOUCAULT, Michel. As palavras e as coisas: uma arquitetura das ciências humanas. São Paulo: Martins Fontes,1992.

_. Vigiar e punir: nascimento da prisão. 36. ed. Petrópolis: Vozes, 2007.

GOMES, Ana Carolina Vimieiro; DALBEN, André. O controle médico-esportivo no Departamento de Educação Física do Estado de São Paulo: aproximações entre esporte e medicina. História, Ciência, Saúde-Manguinhos, v. 18, n. 2, Rio de Janeiro, Abr./Jun. 2011, p. 321-335.

HABERMAS, Jürgen. La technique et la science comme idéologie. Paris: Denoël-Gonthier. 1973.

JOÃO, Renato Bastos; BRITO, Marcelo de. Pensando a corporeidade na prática pedagógica em educação física à luz do pensamento complexo. Revista Brasileira de Educação Física e Esportes, v. 18, n. 3, São Paulo, Jul./Set. 2004, p. 263-272.

JUBÉ, Carolina N. Os "avatares" do corpo rascunho: sobre a formação identitária de jovens universitários na cibercultura. 2010. Dissertação (Mestrado) - Programa de Pós-graduação em Educação Física, Faculdade de Educação Física, Universidade de Brasília, Brasília.

LASO, Eduardo. El racionalismo y la deducción. In: DÍAZ, Esther (Org.) La ciencia y el imaginario social. Buenos Aires: Biblos, 1996, p. 45-63.

LE BRETON, David. Adeus ao corpo. Campinas: Papirus, 2003.

Sinais de identidade: tatuagens, piercings e outras marcas corporais. Lisboa: Miosótis, 2004. 
- A sociologia do corpo. Petrópolis: Vozes, 2006.

—. Individualização do corpo e tecnologias contemporâneas. In: COUTO, Edvaldo Souza; GOELLNER, Silvana Vilodre (Orgs.). O triunfo do corpo: polêmicas contemporâneas. Petrópolis: Vozes, 2012, p. 15-32.

LÉVY, Pierre. O que é o virtual? São Paulo: 34, 1996.

LINHALES, Meily Assbú. A escola e o esporte: uma história de práticas corporais. São Paulo: Cortez, 2009.

MACHADO, Afonso Antônio; ZANETTI, Marcelo Callegari; MOIOLI, Altair. O corpo, o desenvolvimento humano e as tecnologias. Motriz, v. 17, n. 4, Rio Claro, Out./Dez. 2011, p. 728-737.

MAUSS, Marcel. Sociologia e antropologia. 2. ed. São Paulo: Cosac Naify, 2005.

MONTEIRO, Marko. Teatro anatômico digital: práticas de representação do corpo na ciência. História, Ciência, Saúde - Manguinhos, v. 18, n. 3, Rio de Janeiro, Jul./Set. 2011, p. 641-660.

OLIVEIRA, Luiz Albert. Biontes, bióides e borgues. In: NOVAES, Adauto (Org.). O homem-máquina: a ciência manipula o corpo. São Paulo: Cia das Letras, 2003, p. 139-173.

RODRIGUES, David. Corpo, técnica e identidade. In: RODRIGUES, David (Org.). Os valores e as atividades corporais. São Paulo: Summus, 2008, p. 11-26.

SANTAELLA, Lucia. Corpo e comunicação: sintoma da cultura. São Paulo: Paulus, 2004.

SHNEIDER, Omar; FERREIRA NETO, Amarílio. Americanismo e a fabricação do "homem-novo": circulação e apropriação de modelos culturais na Revista Educação Physica (1932-1945). Movimento, v. 14, n. 1, Porto Alegre, Jan./Abr. 2008, p. 135159.

SILVA, Ana Márcia. Das práticas corporais ou porque "narciso" se exercita. Revista Brasileira de Ciências do Esporte, v. 3, n. 17, Campinas, Maio1996, p. 244-251,.

SOARES, Carmen Lúcia. Educação Física: raízes europeias e Brasil. 5. ed. Campinas: Autores Associados, 2012.

SOARES, Carmen Lúcia. Imagens da educação do corpo: estudo a partir da ginástica francesa no século XIX. 3. ed. Campinas: Autores Associados, 2006. 
SUASSUNA, Dulce et alii. A relação corpo-natureza na modernidade. Sociedade e Estado, v. 20, n. 1, Brasília, Jan./Abr. 2005, p. 23-38.

TOURAINE, Alain. Crítica da modernidade. Petrópolis: Vozes, 1994.

VIGARELLO, Georges. Le corps redressé. Paris: Jean Pierre Delarge, 1978.

WIGGERS, Ingrid Dittrich. Crianças desenham novas corporeidades? In: FANTIN, Mônica; GIRARDELLO, Gilka (Orgs.). Liga, roda, clica: estudos em mídia, cultura e infância. Campinas: Papirus, 2012, p. 75-98. 
